\title{
Fracture surfaces of tungsten wires used in fiber-reinforced plasma facing components: effect of potassium doping and high temperature annealing
}

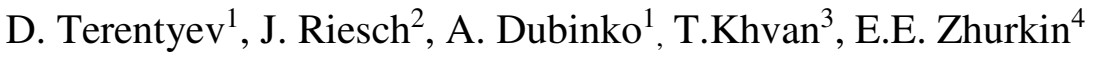 \\ ${ }^{1}$ Structural Materials Group, Institute of Nuclear Materials Science, SCK·CEN, Mol, 2400, Belgium \\ ${ }^{2}$ Max-Planck-Institut für Plasmaphysik, 85748 Garching, Germany \\ ${ }^{3}$ V.N. Karazin Kharkiv National Universit, 4 Svobody Sq., Kharkiv, 61022, Ukraine \\ ${ }^{4}$ Peter the Great St. Petersburg Polytechnic University, St. Petersburg, 195251 Russia
}

\begin{abstract}
We have studied the microstructure of tungsten fibers, which are considered as reinforcement elements for the advanced tungsten composites $\left(\mathrm{W}_{\mathrm{f}} / \mathrm{W}\right)$ known to exhibit pseudo ductile behaviour at room temperature. The potentially negative impact of the high temperature annealing, expected under operation in fusion environment, remains to be explored and mitigated. Doping by potassium is considered as a main option to delay recrystallization and grain growth inside the drawn tungsten wires to a higher temperature. Here, we have performed a systematic analysis of the fracture surface of pure and K-doped tungsten wires which were annealed prior to a uniaxial tensile test. The results demonstrate that the fracture mechanism depends strongly on the annealing temperature and presence of potassium doping. Four fracture mechanisms were clearly distinguished and classified by converting into deformation maps as a function of annealing and testing temperature. By summarizing all previously available results and current ones, one can demonstrate that potassium doping delays massive grain growth (and subsequent loss of strength) by $\sim 600^{\circ} \mathrm{C}$ as compared to the pure $\mathrm{W}$ wire and this positive effect holds for the deformation not only at room temperature by at least up to $500^{\circ} \mathrm{C}$.
\end{abstract}

Keywords: tungsten, fiber, composite, recrystallization, fracture surface.

\section{Introduction}

Tungsten (W) is the plasma-facing material chosen for the ITER divertor and is being candidate material for DEMO ${ }^{1,2}$. Therefore, the investigation of its performance and structural integrity under fusion relevant conditions is one of the major directions in fusion material science. Despite a number of attractive features, bulk tungsten suffers from an intrinsic brittleness ${ }^{3}$ which is even more pronounced after recrystallization and grain coarsening ${ }^{4}$ or/and exposure to energetic neutrons ${ }^{5,6}$. Currently, intensive studies are carried out to mitigate the brittleness of $\mathrm{W}$ by developing composites where drawn tungsten wires serve as a reinforcing element and ensures pseudoductility even at room temperature ${ }^{7-11}$.

Indeed, as-drawn W fiber (henceforth wire) features unique properties, namely: ultra-high strength and room temperature ductility. The latter is determined by the asdrawn microstructure consisting of elongated intertwined grains ${ }^{12,13}$ and a high dislocation density (contained in both grain interior and grain interfaces) ${ }^{14}$. The low temperature ductility has been attributed to the availability of non-screw type dislocations (thus capable to glide already at room temperature), while the high strength was assigned to the small grain size in the transversal orientation causing pronounced Hall-Petch strengthening effect for the load applied along the wire axis ${ }^{15}$.

The operation in a high temperature fusion environment, besides the neutron irradiation embrittlement, will cause thermal spikes (due to plasma instability) such that the surface region of the plasma facing components might reach temperature exceeding threshold for the recrystallization ${ }^{16}$. Under such thermal cyclic loads, the dedicated as-fabricated microstructure might recover and the wires would lose its advantageous properties.

In pure tungsten wire, significant modification of the as-drawn microstructure occurs already at $800^{\circ} \mathrm{C}$, as at this temperature the so-called Hosford structure is lost and the line dislocations are annihilated ${ }^{14}$. When the annealing temperature exceeds $1300^{\circ} \mathrm{C}$, grain morphology modification and grain growth starts to occur ${ }^{17,18}$. Finally, above $1600^{\circ} \mathrm{C}$ the formation of large equiaxed grains is competed. While the wire annealed at $800^{\circ} \mathrm{C}$ is still ductile, annealing at $1300^{\circ} \mathrm{C}$ leads to a full embrittlement.

Potassium doping is known to be an efficient way to improve the resistance of tungsten against grain growth upon annealing ${ }^{19}$. Recently, a dedicated set of mechanical tests involving pure $\mathrm{W}$ and K-doped wires has been performed using the wires pre-annealed in the wide temperature range to explore the margin within which potassium doping retains the wire strength ${ }^{9,20}$.

In the case of pure wire, it is found that $1300^{\circ} \mathrm{C}$ annealing causes strong reduction of the tensile strength (more than a factor of two as compared to the as-drawn state) and a loss of ductility at room temperature. In the case of K-doped wires, the results of mechanical tests have demonstrated that some plastic deformability at room temperature remains even if the wire is annealed up to $2100^{\circ} \mathrm{C}$, while the ultimate tensile strength remains rather high (0.8 GPa vs. $2.3 \mathrm{GPa}$ in the non-annealed state). The tests at elevated temperature, revealed that the 
mechanical response changes as the annealing temperature increases from 1900 to $2100^{\circ} \mathrm{C}$. The yield stress goes below $300 \mathrm{MPa}$ and strain hardening is practically absent. Thus, the severe impact of the annealing in the case of $\mathrm{K}$-doped wires occurs above $1900^{\circ} \mathrm{C}$.

In this work, we apply a systematic microstructural investigation of the fracture surface of the abovementioned wires. The purpose of this action is to classify the fracture mechanisms and validate the conclusions, so far based on the results of the mechanical tests, using alternative microstructural measurements.

\section{Experimental procedures}

Drawn pure and potassium doped (60-75 ppm) tungsten wires, similar to the wire used in $\operatorname{Ref}^{8,10}$ were provided by the OSRAM GmbH, Schwabmünchen. The diameter of the doped wire was measured to be $148.7 \pm$ $0.2 \mu \mathrm{m}^{10}$. Measurements were performed by high resolution optical microscope. The wire was cut into pieces of $100 \mathrm{~mm}$ and these pieces were annealed at 1000 (only pure W), 1300, 1600, 1900, 2100, 2300 (only Kdoped wire) ${ }^{\circ} \mathrm{C}$. The annealing was done in a tube furnace under hydrogen-controlled atmosphere at OSRAM $\mathrm{GmbH}$ for $30 \mathrm{~min}$ at each scheduled temperature.

The detailed description of the mechanical tests is provided in Ref. ${ }^{20}$, here we provide only brief description. A constant displacement with a cross-head speed of 5 $\mu \mathrm{m} / \mathrm{s}$ was applied until fracture using the load cell with maximum load of $0.2 \mathrm{kN}$. The load, measured by a strain gauge, was registered with a frequency of $0.3 \mathrm{~Hz}$. The relative error on the measurement of the pull rod displacement is $\pm 0.1 \%$.

The fracture surface of the tested samples was inspected by SEM. The conclusion on the prevailing type of the microstructure was based on three to five wires examined for each test condition. All SEM images were acquired using a secondary electron detector, so as to effectively reveal the small features $(<1 \mu \mathrm{m})$ on the surface of the broken wires. The employed scanning electron microscope was a JEOL JSM-6610LV (JEOL, Tokyo, Japan) and the operating conditions were: $20 \mathrm{kV}$ accelerating voltage and 12-20 mm working distance. For every test condition (i.e. $\mathrm{T}_{\text {anneal }}$ and $\mathrm{T}_{\text {test }}$ ) at least four wires were inspected to make sure that the type of the fracture surface is indeed representative. In total, we have investigated four annealing conditions for each type of the wire (i.e. pure and K-doped one) and the fracture surface of the as-fabricated wires is studied as well.

\section{Results and discussion}

Inspection of the fracture surface of the broken wires has revealed four types of the fracture morphology. These are presented in Fig. 1 and for each type of the fracture mode two representative SEM images are provided to show the whole wire cross-section and some zoomed features. The first type of the fracture morphology corresponds to the ductile fracture which occurred by the grain boundary deformation and delamination. Fig.1a shows the so-called knife-edge pattern of delaminated and necked grains. These grains are elongated in the direction coinciding with the wire axis. Although each individual grain necked nearly to the $100 \%$ of the reduction area, the whole wire exhibits a neck with the reduction area of 30$80 \%$ depending on the annealing and deformation temperature. Indeed, the plastic deformation occurs thanks to the sub-structure of the curled grains, which are well characterized by electron back scatter diffraction (EBSD) in earlier works ${ }^{14}$. The presence of large radial cracks heading from the center to the surface is also very typical for such fracture. The example presented in Fig.1a corresponds to the K-doped wire annealed at $1600^{\circ} \mathrm{C}$ and tested at room temperature.

If one considers a side view, the profile of the necking region reminds a bullet, which is why we shall refer to such fracture morphology as "bullet-like". For such type of fracture, it was possible to evaluate the necking diameter, on the basis of five successfully tested wires, following the methodology presented in Ref. ${ }^{21}$. The evolution of the neck diameter as a function of the annealing temperature is shown in Fig.2 for the wires tested at room temperature. For the pure $\mathrm{W}$ wire, the neck diameter decreases with the annealing temperature up to $1300^{\circ} \mathrm{C}$, which demonstrates that the wire experiences a larger deformation in the necking region prior to fracture. After annealing at $1600^{\circ} \mathrm{C}$, the diameter of the fractured wire goes up and becomes equal to the initial dimension of wire - meaning that no necking process occurred. Such transition can be taken as a signature of brittle failure. In the case of $\mathrm{K}$-doped wire, no sharp transition is seen up to $2100^{\circ} \mathrm{C}$, and the necking region is observed for all probed annealing temperatures.

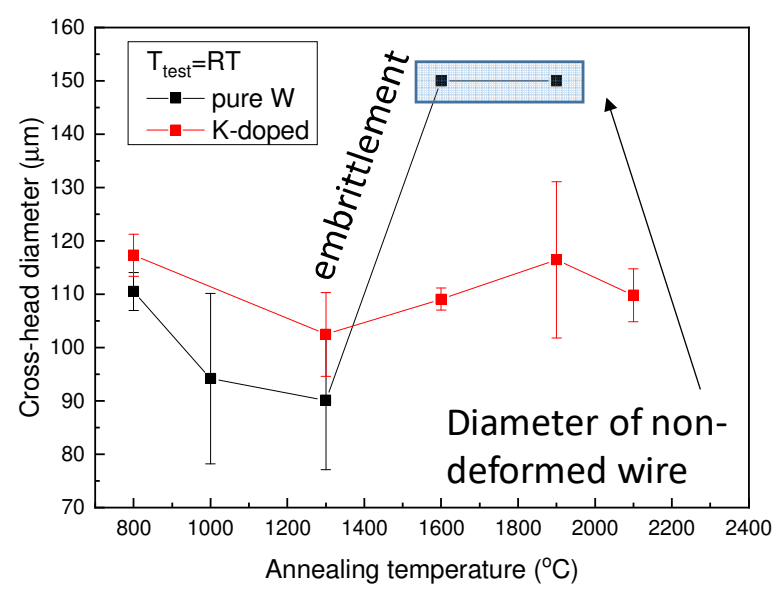

Fig. 2. Diameter of the neck of the deformed wire as a function of annealing temperature. Filled blue rectangular shows the diameter of the non-deformed wire. K-doped wire annealed at $2300^{\circ} \mathrm{C}$ was tested at $100^{\circ} \mathrm{C}$ and at higher temperature.

The second type of fracture, shown in Fig.1b, was regularly observed at elevated temperature on the wires annealed above primary recrystallization temperature, which is $1300^{\circ} \mathrm{C}$ for pure $\mathrm{W}$ wire and $2100^{\circ} \mathrm{C}$ for the $\mathrm{K}$ doped wire, as discussed in recent works where the EBSD study was applied ${ }^{22}$. Here, the wire was fractured by the crack that was propagating across the wire and deflecting each time when hitting new grain boundary. The terrace- 
like pattern can be seen on the bottom micrograph of Fig.1b. This points to the fact that the ductility of grains was reduced and crack advancement caused intergranular fracture. This type of fracture was always seen as transition from ductile bullet-like fracture patter to the brittle cleavage. This fracture mode occurs prior the secondary recrystallization stage as long as the annealing did not yet remove elongated character of the grains, but it already resulted in the modification of the sub-grain structures (curly grains).

Transgranular cleavage was the third type of the fracture surface observed, see Fig.1c. On the zoomed micrographs, one can see the river patterns and facets of grans through which the crack has propagated. The example shown corresponds to the pure $\mathrm{W}$ wire annealed at $1600^{\circ} \mathrm{C}$ and deformed at room temperature. The fracture is purely brittle. Compare Fig.1a and Fig.1c to appreciate the effect of potassium doping. Unlike pure $\mathrm{W}$ wire, the K-doped wire preserves the fine grain structure and therefore exhibits ductile fracture.

The fourth type of the microstructure is complete $100 \%$ necked wire, as shown in Fig.1d. Such fracture surface morphology is observed on the wires that undergone high temperature annealing and therefore the secondary recrystallization (i.e. massive grain growth), in combination with deformation at elevated temperature where the classical dislocation-mediated plasticity is activated. The wire is necked to a single edge likely via the nucleation of dislocations from the surface and their movement inside the wire which is nearly free of the structural defects like bulk dislocations and grain boundaries. Sometimes, the edges of the wire contain traces of local cleavage (see Fig.1d zoomed micrograph), but most of the fracture surface area is filled with the wavy patterns of deformation slip bands (small steps on the surface).

The correspondence between each type of the fracture morphology and the test condition is shown in Fig.3. It is easily seen that each curve exhibits transition from the bullet ductile neck to the cleavage or neck-to-edge fracture. Cleavage occurs in the tests performed at room temperature (Fig.3a) and $300^{\circ} \mathrm{C}$ (Fig.3b), while neck-toedge at $300^{\circ} \mathrm{C}$ and $500^{\circ} \mathrm{C}$ (Fig.3c). In the case of pure $\mathrm{W}$, ductile deformation occurs in the wire annealed up to $1300^{\circ} \mathrm{C}$. It can be easily seen that for each test temperature, potassium doping shifts the deformation curve to the right, thus extending the range of ductile deformation by $600^{\circ} \mathrm{C}$.

To demonstrate how the fracture surface morphology is related with the strength of the wire, we have plotted the normalized ultimate tensile strength (UTS) as a function of the fracture mechanism in Fig.4. The results are plotted for each test temperature. UTS is normalized by its nominal value obtained for the as-received wire at the corresponding test temperature. Nominal value for UTS of pure W wire is $2400 \mathrm{MPa}(\mathrm{RT}), 2025 \mathrm{MPa}$ $\left(300^{\circ} \mathrm{C}\right)$ and $1650 \mathrm{MPa}\left(500^{\circ} \mathrm{C}\right)$. Nominal value for UTS of $\mathrm{K}$-doped wire is $2350 \mathrm{MPa}(\mathrm{RT}), 1915 \mathrm{MPa}\left(300^{\circ} \mathrm{C}\right)$ and $1700 \mathrm{MPa}\left(500^{\circ} \mathrm{C}\right)$, as obtained in $\operatorname{Ref}^{20}$.
Several statements can be drawn from Fig.4. As long as the ductile deformation occurs by the delamination (i.e. type 1 fracture), the strength of the wire, irrespectively being pure or $\mathrm{K}$-doped one, is reduced to $50 \%$ compared to the initial value. Whereas the change to brittle fracture causes further reduction of the wire strength down to $40 \%$ at room temperature. The ductile deformation resulting in the complete necking (i.e. neck-to-edge fracture observed in tests done at $300^{\circ} \mathrm{C}$ and $500^{\circ} \mathrm{C}$ ) causes the reduction of the wire strength down to $10 \%$ of the initial value, which is again observed for both types of wires. Thus, irrespective of the presence of K-doping, we observe rather good correlation between the type of the fracture surface pattern and relative reduction of the wire strength. Therefore, such information can be used to analyse and reconstitute the actual mechanical resistance of the fibers operating in the $\mathrm{W}_{\mathrm{f}} / \mathrm{W}$ composite by inspecting the fracture surface of the broken fibers.

\section{Summary and conclusions}

We have systematically analysed the fracture surface of the pure and $\mathrm{K}$-doped $\mathrm{W}$ wires annealed in the temperature range of $1000-2300^{\circ} \mathrm{C}$ and then tested by uniaxial deformation in the temperature range of 22 $500^{\circ} \mathrm{C}$. The earlier results of the mechanical tests ${ }^{8,9,20}$ have shown that potassium doping improves the resistance of the wire against annealing-induced recrystallization. However, both wire types undergo a drastic reduction of tensile strength if annealed above a certain temperature, which is $1300^{\circ} \mathrm{C}$ for pure wire and $1900^{\circ} \mathrm{C}$ for doped wire, respectively. The microstructural analysis performed here helps to explain the difference.

Four well distinct types of the fracture surface were revealed. As the annealing temperature raises up, the ductile deformation occurring by grain boundary sliding and delamination changes abruptly to cleavage or neckto-edge, depending on the deformation test temperature. Cleavage prevails at room temperature, while complete neck-to-edge fracture occurs at $300^{\circ} \mathrm{C}$ and above. In the transition between two states (i.e. ductile delamination and brittle cleavage), deformation occurs by the transgranular fracture such that the crack propagates across elongated grain boundaries and experiences a multiple deflections eventually forming a wedge-like fracture surface. Based on the presented results and recently obtained EBSD data ${ }^{22}$, the threshold temperature for the secondary recrystallization stage in the pure wire is $1300-1500^{\circ} \mathrm{C}$, and for $\mathrm{K}$-doped wire is $1900-2100^{\circ} \mathrm{C}$. Hence, potassium doping shifts the secondary recrystallization stage by $\sim 600^{\circ} \mathrm{C}$. The same conclusion can be made on the basis of the deformation maps presented in Fig. 3 for each tensile test temperature.

Up to now, a series of works demonstrated exclusively positive effect of potassium doping on the mechanical properties of the wire. The next critical step is to explore the impact of neutron irradiation on the wire strength and ductility, and the current assessment will help rationalization of the fracture mode of the wires inside the irradiated composites. Ion irradiation and nanoindentation can be a first step towards such assessment. 


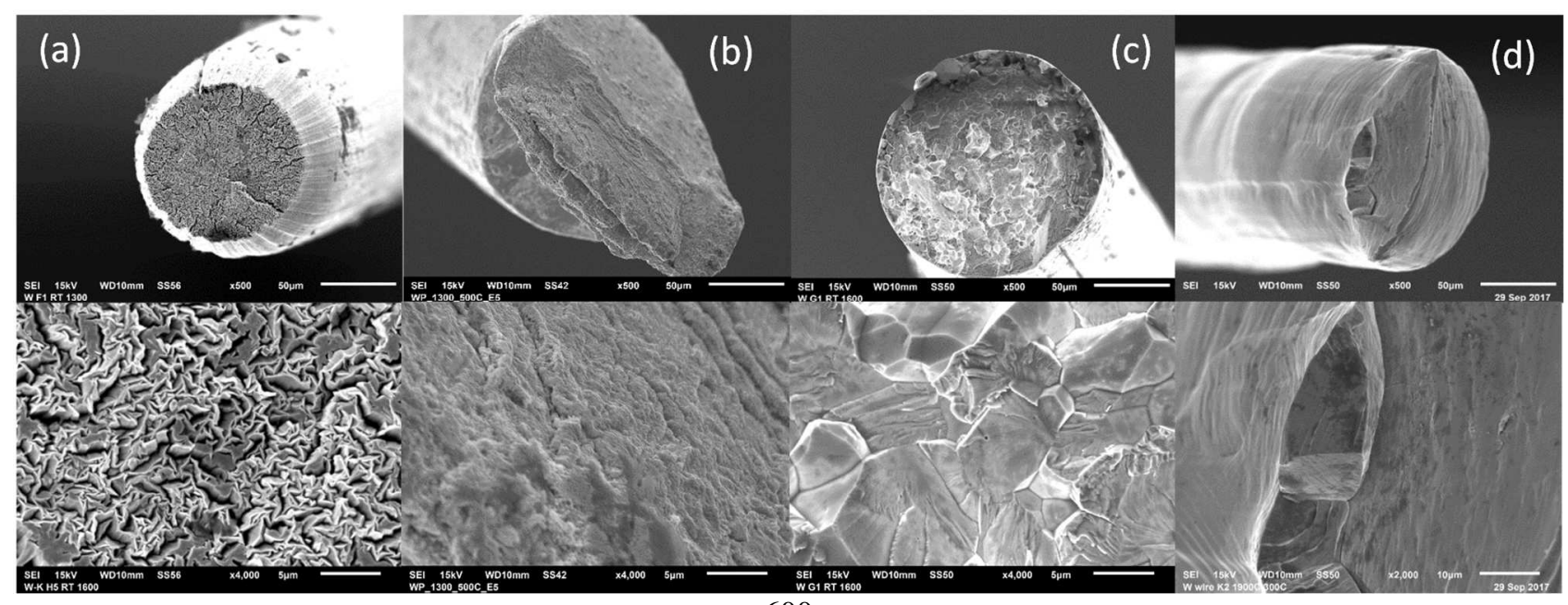

600

Fig. 1. Fracture surface of the wires representing four typical microstructures: (a) bullet neck, K-doped wire, $\mathrm{T}_{\mathrm{ann}}=1600^{\circ} \mathrm{C}, \mathrm{T}_{\text {test }}=\mathrm{RT}$; (b) crack deflection, pure $\mathrm{W}$ wire, $\mathrm{T}_{\mathrm{ann}}=1300^{\circ} \mathrm{C}, \mathrm{T}_{\text {test }}=500^{\circ} \mathrm{C}$; (c) Cleavage, pure $\mathrm{W}$ wire, $\mathrm{T}_{\mathrm{ann}}=1600^{\circ} \mathrm{C}$, $\mathrm{T}_{\text {test }}=\mathrm{RT}$; and (d) neck-toedge, pure $\mathrm{W}$ wire, $\mathrm{T}_{\mathrm{ann}}=1900^{\circ} \mathrm{C}, \mathrm{T}_{\text {test }}=300^{\circ} \mathrm{C}$.
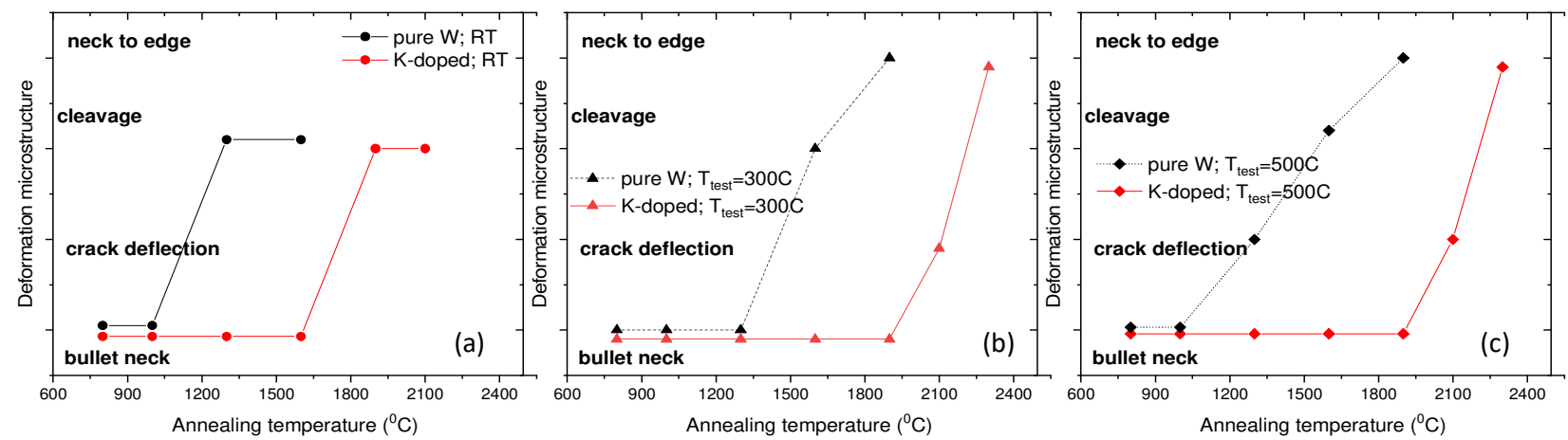

Fig. 3. Deformation mechanism map as a function of the annealing temperature $\left(800^{\circ} \mathrm{C}\right.$ corresponds to the as-received state) for the wires deformed at (a) Room Temperature; (b) $300^{\circ} \mathrm{C}$ and (c) $500^{\circ} \mathrm{C}$.

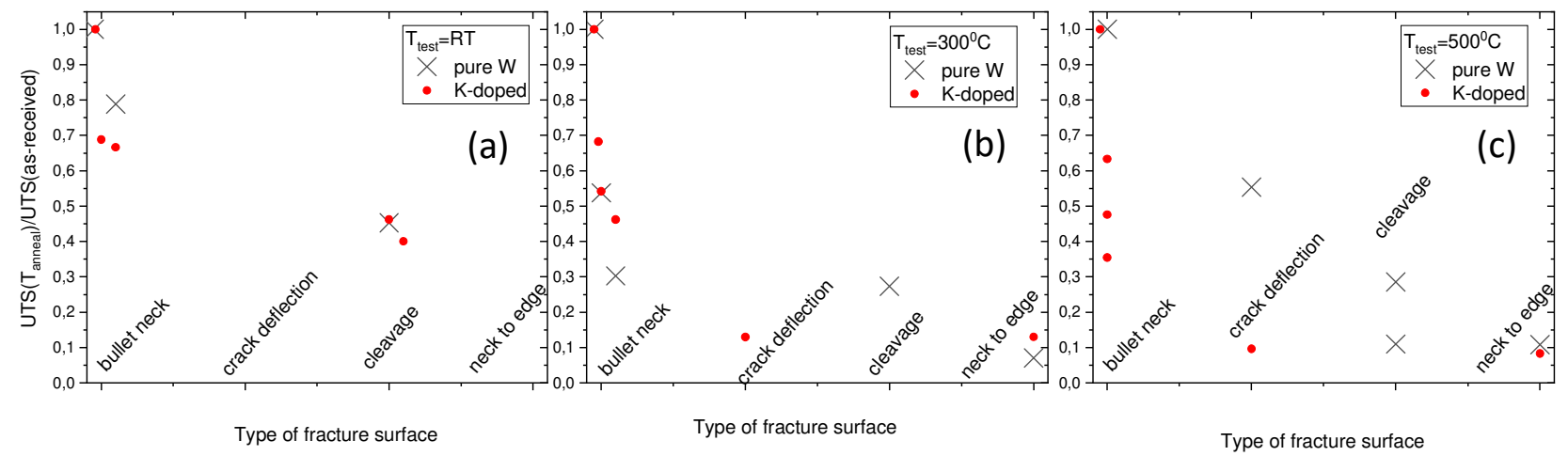

Fig. 4. Ultimate tensile strength normalized by its nominal value (UTS for as-received wire tested at the corresponding temperature) depending on the type of the fracture surface plotted for the tests done at (a) room temperature; (b) $300^{\circ} \mathrm{C}$ and (c) $500^{\circ} \mathrm{C}$.

\section{Acknowledgments}

This work has been carried out within the framework of the EUROfusion Consortium and has received funding from the Euratom research and training programme 20142018 under grant agreement No 633053. The views and opinions expressed herein do not necessarily reflect those of the European Commission. The authors want to 
acknowledge support by OSRAM GmbH, Schwabmünchen, Germany for providing the tungsten wire and performing the annealing.

\section{References:}

1. Pintsuk, G., Comprehensive Nuclear Materials (2012) 4, 551

2. Rieth, M., et al., Journal of Nuclear Materials (2013) 432 (1-3), 482

3. Giannattasio, A., et al., Philosophical Magazine (2010) 90 (30), 3947

4. Yih, S., and Wang, C., Tungsten: Source, Metallurgy, Properties, and Applications (1979) (Springer Science+Business Media New York)

5. Steichen, J. M., Journal of Nuclear Materials (1976) 60 (1), 13

6. Gorynin, I. V., et al., Journal of Nuclear Materials (1992) 191, 421

7. Linsmeier, C., et al., Nuclear Fusion (2017) 57

(9)

8. Terentyev, D., et al., Int J Refract Met H (2017)

66, 127

9. Terentyev, D., et al., Int J Refract Met H (2018)

66, 127

10. Riesch, J., et al., Physica Scripta (2016) T167

11. Neu, R., et al., Nuclear Materials and Energy (2017) 12, 1308

12. Meieran, E. S., and Thomas, D. A., Transactions of the Metallurgical Society of AIME (1965) 233, 937

13. Barna, A., et al., High Temperatures - High Pressures (1978) 10 (2), 197

14. Zhao, P., et al., Int J Refract Met $H$ (2017) 68,

29

15. Riesch, J., et al., Physica Scripta (2017) 2017, 014032

16. Hirai, T., et al., Nuclear Materials and Energy (2016) 000, 1

17. Alfonso, A., et al., Journal of Nuclear Materials (2014) 455 (1-3), 591

18. Yu, M., et al., Fusion Engineering and Design (2017) 125, 531

19. Briant, C. L., and Bewlay, B. P., Mrs Bull (1995) 20 (8), 67

20. Terentyev, D., et al., International Journal of Refractory Metals and Hard Materials (2018) 76, 226

21. Riesch, J., et al., IOP Conf. Series: Materials Science and Engineering (2016) 139, 012043

22. Terentyev, D., et al., International Journal of Refractory Metals and Hard Materials (2018), submitted 